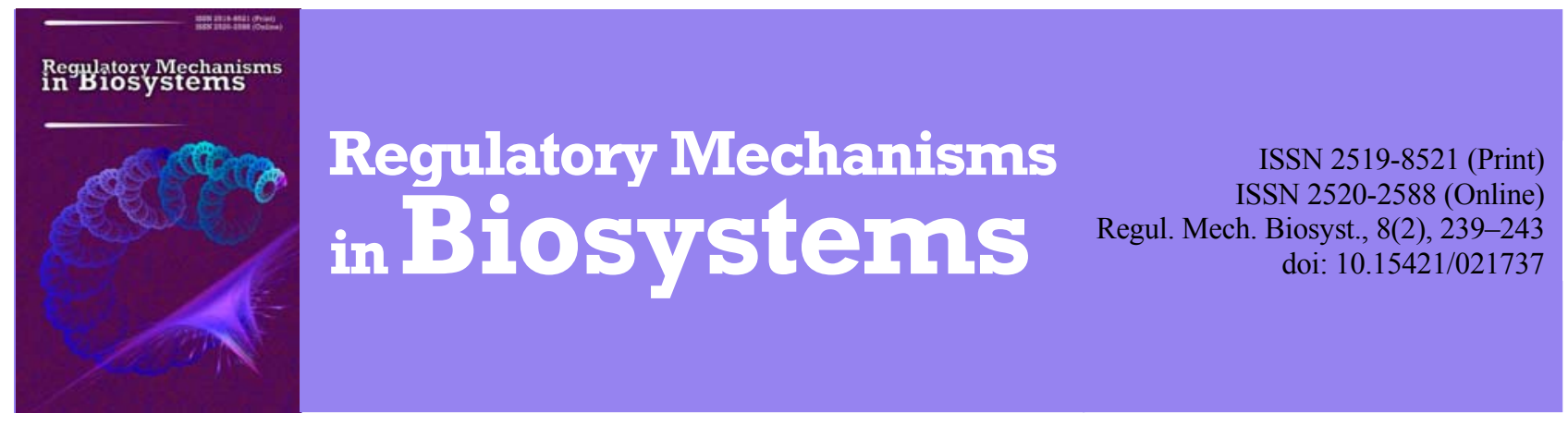

\title{
The features of vegetative regulation of the heart rate in athletes with different levels of perception and processing of visual information
}

\author{
O. Skyba, L. Pshenychna, O. Ustymenko-Kosorich \\ Sumy State Pedagogical University named after A. S. Makarenko, Sumy, Ukraine
}

Article info

Received 28.04.2017

Received in revised form 14.05.2017

Accepted 16.05.2017

Sumy State Pedagogical University named after A. S. Makarenko,

Romenskaya Str., 87,

Sumy, Ukraine.

Tel.: +38-066-474-36-74.

E-mailskiba_olga@mail.ua
Skyba, O., Pshenychna, L., \& Ustymenko-Kosorich, O. (2017). The features of vegetative regulation of the heart rate in athletes with different levels of perception and processing of visual information. Regulatory Mechanisms in Biosystems, 8(2), 239-243. doi:10.15421/021737

The study involved 32 children aged from 11-12 who were receiving training in sports schools in Sumy. The children were divided into three study groups with high, medium and low levels of sensorimotor reactivity, defined in terms of complex visual-motor response. The study methods were psychophysiological, cardiointervalography, mathematical and statistical. We found that the majority of individuals with a medium level of sensorimotor reactivity possessed vegetative tonus, characterized by background emphotony, while sympathicotonia was prevalent in the group of athletes with a high level of sensorimotor reactivity, in comparison with those with medium and low levels of sensorimotor reactivity. Vegetative imbalance that manifests via hypersympaticotonic reactivity occurred among athletes with high and medium levels of sensorimotor reactivity, which is the evidence of stress on the cardiovascular system, decline of adaptive capacity of the organism in the individuals investigated. Shorter latent periods of complex visual-motor responses (LP SR 1-3 and LP SR 2-3) were observed among athletes with hypersympaticotonic vegetative reactivity, compared to sportsmen with normal type of vegetative reactivity. Analysis of indicators of heart rate variability revealed an increased activity of the sympathoadrenal system in athletes with a high level of sensorymotor response, which is confirmed by significantly lower values of SDNN and RMSSD in comparison with athletes with a low level of sensorymotor response. The activation of central regulation in athletes with a high level of sensorimotor responses also show significantly higher values IN and Amo, in comparison with athletes with a low level of sensorymotor response. The figures IN (47.7\%), and Amo (45.3\%) were those most effected by the level of sensorimotor reactivity. Less effected were figures of SDNN (43.1\%), which reflects general heart rate variability and RMSSD (43.1\%), which reflects high frequency components of heart rate. Analysis of change in dynamics of figures of heart rate variability provides evidence of higher activity of the sympathoadrenal system in athletes with a high level of sensorimotor reactivity, which facilitates increased stress on heart rhythm vegetative regulation mechanisms, accompanied by decline of parasympathetic influences of the vegetative nervous system.

Keywords: visual-motor reaction; vegetative tonus; vegetative reactivity; cardiointervalography; sports activity

\section{Особливості вегетативної регуляції ритму серця у спортсменів із різним рівнем сприйняття та переробки зорової інформації}

\author{
О. О. Скиба, Л. В. Пшенична, О. А. Устименко-Косоріч \\ Сумський державний педагогічний університет імені А. С. Макаренка, Суми, Украӥна
}

Оцінювали функціональний стан вегетативної нервової системи за показниками варіабельності серцевого ритму 3 визначенням вихідного вегетативного тонусу та вегетативної реактивності у спортсменів із різним рівнем сенсомоторної реактивності. Обстежено 32 дитини віком 11-12 років, яких поділено на три групи дослідження 3 високим, середнім та низьким рівнями сенсомоторної реактивності, визначеним за показником складної зорово-моторної реакції. Вегетативний тонус, що характеризувався фоновою ейтонією, визначений серед більшості спортсменів із середнім рівнем сенсомоторного реагування, а симпатикотонія вірогідно переважала серед групи спортсменів із високим рівнем сенсомоторного реагування, порівняно із спортсменами із середнім та низьким його рівнями. Вегетативний дисбаланс, що проявлявся гіперсимпатикотонічною реактивністю, визначався серед спортсменів із високим та середнім рівнями сенсомоторного реагування, що свідчить про напруження в них функціонування серцево-судинної системи, зниження адаптаційних можливостей організму. Визначено коротші латентні періоди складних зорово-моторних реакцій (РВ1-3 та РВ2-3) у спортсменів із гіперсимпатикотонічною вегетативною реактивністю, порівняно із спортсменами 3 нормальним типом вегетативної реактивності. Вагомий внесок рівня сенсомоторної реактивності визначено для показників IN (47,7\%) та Аmo (45,3\%). Дещо менший вплив установлено для показника SDNN (43,1\%), що відображає загальну варіабельність серцевого ритму та RMSSD (43,1\%), який свідчить про високочастотні компоненти серцевого ритму. Аналіз спрямованості змін визначених показників варіабельності серцевого 
ритму вказує на підвищену активність симпато-адреналової системи у спортсменів із високим рівнем сенсомоторного реагування, який сприяє збільшенню напруження механізмів вегетативної регуляції серцевого ритму, що супроводжується зниженням парасимпатичних впливів із боку вегетативної нервової системи.

Ключові слова: зорово-моторні реакції; вегетативний тонус; вегетативна реактивність; кардіоінтервалографія; спортивна діяльність

\section{Вступ}

Адаптаційно-функціональна перебудова в організмі у відповідь на стимул відбувається за допомогою нейрогенної та гормонально-гуморальної ланок регуляції, що супроводжується зміною активності центральної нервової системи (ЦНС) та активацією гіпоталамо-гіпофізарної системи, яка відповідає за підтримання гомеостазу (Tufnell, 2005; Coppel, 2015; Kolesnikova et al., 2015).

До об'єктивних критеріїв поточного контролю функціонального стану ЦНС належать показники сенсомоторних реакцій різного ступеня складності, реалізація яких включає сприйняття сенсомоторного стимулу, його аналіз, прийняття рішення та моторну відповідь тощо (Herpin et al., 2010; Korobeynikov and Korobeynikova, 2014; Bellenger et al., 2016; Rovnyj and Romanenko, 2016). Проте складні та прості сенсомоторні функції мають не однакову фізіологічну природу та відображають функціональний стан різних систем. Нейрофізіологічні механізми простих зорово-моторних реакцій повязані 3 пірамідно-стріальним рівнем організації, що включає пірамідний (кортикальний) i екстрапірамідний (субкортикальний) контроль (Rizzolatti et al., 2000; Nakahara et al., 2001; Sanes, 2003; Opris, 2005; Golovin et al., 2016; Crollen et al., 2017). Виконання простого сенсомоторного акту здійснюється простою рефлекторною дугою без широкої мобілізації функціональних систем організму. Механізми, що забезпечують виконання складної реакції, характеризують реактивність, активацію та регуляцію вищого рівня (кортикального) за участю фронтально-лімбічного комплексу 3 активізацією ендокринної, серцево-судинної, дихальної та інших систем організму (Gallese et al., 2009; Makarenko and Lyzohub, 2011; Zaichkowsky, 2012).

Як провідний фактор ефективності реалізації сенсомоторних реакцій виступає функціональний стан організму, що визначається ступенем активції систем організму, які детермінують результативність певної діяльності (Bundzen et al., 2005; Korobejnikov et al., 2013; Shutova and Murav'eva, 2013).

Спортивна діяльність із властивими ій інтенсифікацією тренувального процесу та граничними фізичними навантаженнями на сучасному етапі розглядається як вид екстремальної діяльності людини, що може спричинити зрив механізмів адаптації організму спортсменів (Blascovich et al., 2004; Rimmele et al., 2009; Bartczak et al., 2016; Nicolas et al., 2016).

Аналіз останніх досліджень і публікацій свідчить, що до ранніх ознак порушення адаптації спортсменів до факторів навчально-тренувального процесу належить дисбаланс вегетативної нервової системи, що в подальшому може викликати розвиток передпатологічних і патологічних станів (Kraus et al., 2013; Nikolaeva and Merenkova, 2014). Основним патогенетичним механізмом багатьох серцево-судинних захворювань у спортсменів слугує вегетативна дисфункція (Phukan et al., 2011; Sartor et al., 2013). Вторинні вегетативні розлади належать до однієї із провідних причин ранніх ознак порушення стану здоров'я у спортсменів (Nekhanevych, 2014).

Поширеність вегетативних розладів визначена в широкому діапазоні від 6,2\% до $36,5 \%$ осіб (Suetake et al., 2010). Відмінності за частотою виявлення вегетативних порушень пояснюються неоднозначністю в їх етіопатогенетичному трактуванні, використанням різних методичних підходів під час їх діагностики та самих методів діагностики, а також відсутністю єдиних критеріїв оцінювання результатів обстеження (Thayer et al., 2010).

Таким чином, у системі динамічного контролю за станом здоров'я юних спортсменів провідна роль повина належати оцінюванню функціонального стану серцево-судинної системи та вегетативної регуляції для виявлення ранніх ознак дезадаптації, оскільки зниження ступеня адаптації може супроводжуватися переходом як до преморбідних, так і патологічних станів із ростом серцево-судинної захворюваності.

Мета дослідження - визначення особливостей вегетативної регуляції ритму серця у спортсменів із різним рівнем сприйняття та переробки зорової інформації.

\section{Матеріал і методи досліджень}

Комісія з питань біоетики Сумського державного педагогічного університету імені А. С. Макаренка встановила (протокол № 10 від 28.04.2014р.), що всі обстеження проведені відповідно до основних біотичних норм Гельсінської декларації Всесвітньої медичної асоціації про етичні принципи проведення науково-медичних досліджень за участі людини (1964-2000), Декларації принципів толерантності (1995), Універсальної декларації з біоетики та прав людини (1997), Конвенції Ради Свропи з прав людини та біомедицини (1997), наказу МОЗ України від 13.02.2006 p. № 66. Батьки обстежуваних давали письмову згоду для участі в дослідженнях. Вжито необхідних заходів для забезпечення анонімності обстежуваних.

У дослідженні брали участь 32 дітини віком 11-12 років, які займались панкратіоном у групах попередньої базової підготовки у системі дитячо-юнацьких спортивних шкіл м. Суми.

Особливості сенсомоторного реагування спортсменів визначали за показниками сенсомоторної реактивності за допомогою програмного забезпечення комплексу «Діагност-1» (Makarenko and Lyzohub, 2011).

Сенсомоторну реактивність оцінювали за величиною латентного періоду простої зорово-моторної реакції (ПЗМР), латентних періодів реакції вибору одного подразника із трьох (PB1-3) та двох із трьох сигналів (PB2-3). Визначення латентних періодів зорово-моторних реакцій різної складності проведено в режимі «оптимального ритму». Завдання у визначеному режимі дозволяло реєструвати середню величину латентного періоду простої та складної зорово-моторних реакцій $(x)$, середнє квадратичне відхилення (SD) та похибку середнього значення (m).

Рівень сенсомоторного реагування (низький, середній та високий) визначали методом сигмальних відхилень $(x \pm \mathrm{SD})$ за показником складної зорово-моторної реакції (РВ 1-3).

Залежно від рівня сенсомоторного реагування, дітей розподілено на три групи:

- I група - спортсмени із низьким рівнем сенсомоторного реагування, $\mathrm{n}=9$;

- II група - спортсмени із середнім рівнем сенсомоторного реагування, $\mathrm{n}=13$;

- III група - спортсмени із високм рівнем сенсомоторного реагування, $\mathrm{n}=10$.

Для оцінювання функціонального стану вегетативної нервової системи (BНC) проводили дослідження варіабельності серцевого ритму (ВСР) із використанням апаратно-програмного комплексу «КардіоСпектр» АТ Солвейг відповідно до вимог Міжнародного стандарту (Task Force of the European Society of Cardiology and the North American Society of Pacing and Electrophysiology, 1996) для коротких записів.

Проводили аналіз двох категорій ВСР: часовий аналіз (time domain results) та частотний аналіз (frequency - domain results). $\mathrm{V}$ часовому аспекті здійснено оцінювання показників $\mathrm{NN}$ - ряд нормальних R-R інтервалів із виключенням екстрасистол; SDNN - стандартне відхилення NN інтервалів; RMSSD - квадратний корінь із середнього значення квадратів різниць величин послідовних інтервалів R-R; $\mathrm{pNN}_{50}$ - відсоток кардіоінтервалів, що відрізнялися від сусідніх більше ніж на 50 мс від 
загальної кількості кардіоінтервалів; $\mathrm{M}_{0}$ - значення кардіоінтервалу, яке найчастіше зустрічається в даному динамічному ряді; $\mathrm{A}_{\mathrm{m} 0}$ - кількість кардіоінтервалів, що відповідає значенню моди (у \% до обсягу вибірки), IN - індекс напруження.

У частотній ділянці визначали абсолютні значення показників TF (Total Frequency) - загальної потужності спектра; HF (High Frequency) - потужності високочастотних коливань спектра, яка характеризує дихальний компонент ВСР, пов'язаний із парасимпатичним регулюванням; LF (Low Frequency) - потужності низькочастотних коливань спектра, який відображає активність підкіркового вазомоторного центру та пов'язаний із симпатичною ланкою регуляціï; VLF (Very Low Frequency) - потужності наднизькочастотних коливань спектра, який відображає активність надсегментарних відділів автономної нервової системи та нейрогуморальний компонент регулювання, LF/HF - коефіцієнт, який відображає баланс вегетативних впливів.

Комп'ютерний аналіз включав визначення вихідного вегетативного тонусу: перевага тонусу парасимпатичного (ваготонія) чи симпатичного (симпатикотонія) відділу ВНС, баланс (ейтонія).

Реєстрацію кардіоінтервалограми проводили у горизонтальному положенні обстежуваних (лежачи на спині), у стані відносного спокою у першій половині дня протягом п'яти хвилин.

Визначення реактивності ВНС здійснювали за допомогою активної ортостатичної проби (Vejn, 2003; Fedorowski and Melander, 2013).

Після проведення фонового запису кардіоінтервалограми, обстежуваний без різких рухів приймав вертикальне положення, в якому проводили повторний запис кардіоінтервалограми.

Тип вегетативної реактивності визначали за відношенням $\mathrm{IN}_{2}$ (індекс напруження в ортостазі) до $\mathrm{IN}_{1}$ (індекс напруження у стані відносного спокою) з виділенням нормального, гіперсимпатикотонічного та асимпатикотонічного типів (Majdannyk et al., 2014).

Статистичну обробку результатів здійснювали загальноприйнятими методами варіаційної статистики за допомогою пакетів програм Statistica 8.0 (StatSoft Inc., USA). Розраховували середні значення (x), стандартні відхилення (SD) та величини похибки середнього (m).

Для номінальних змінних розраховували взаємозв'язок за таблицями спряженності та критерієм $\chi^{2}-$ Пірсона.

Відмінності між вибірками у випадках порівняння їх середнього значення, розподілені за нормальним законом, оцінювали за параметричним t-критерієм Стьюдента. Вірогідність відмінностей оцінювали на рівні $\mathrm{P}<0,05$.

Для визначення відмінностей показників ВСР у групах спортсменів із різним рівнем сенсомоторної реактивності та впливу сенсомоторних функцій на вегетативний гомеостаз застосовано дисперсійний аналіз.

Оцінювання впливу сенсомоторних функцій на показники BCP спортсменів здійснено за критерієм Фішера (F).

Дослідження виконано згідно 3 планом науково-дослідницької роботи кафедри медико-біологічних основ фізичної культури Сумського державного педагогічного університету імені А. С. Макаренка за темою «Фізіолого-гігієнічний супровід здоров’язбережувальної діяльності закладів освіти», № держреєстрації $0113 \mathrm{U} 004662$.

\section{Результати}

За результатами дослідження встановлено залежність вихідного вегетативного тонусу спортсменів від рівня їх сенсомоторної реактивності $\left(\chi^{2}=11,7, \mathrm{P}<0,05\right)$.

Аналіз вегетативного тонусу спортсменів із середнім та низьким рівнями сенсомоторної реактивності вказує на перевагу в них ейтонії $(77,8 \pm 11,5 \%, 50,0 \pm 16,7 \%$, відповідно), тоді як у структурі вегетативного тонусу спортсменів із високим рівнем сенсомоторної реактивності ейтонія визначалась у $5,7 \pm 7,3 \%$ обстежених ( $\mathrm{P}<0,001-0,05)$.
Серед спортсменів із високим рівнем сенсомоторної реактивності частка осіб із симпатикотонією була вірогідно вищою $(94,3 \pm 7,3 \%)$ порівняно зі спортсменами із середнім та низьким її рівнями $(22,2 \pm 11,5 \%$ і $25,0 \pm 14,4 \%$ відповідно, $\mathrm{P}<$ 0,001-0,01), що свідчить про напруження механізмів вегетативної регуляції серцевого ритму у дітей із високим рівнем сенсомоторної реактивності.

Спрямованість вегетативних зрушень у відповідь на ортостаз пов'язана з фоновим рівнем активності. Встановлено, що вегетативна реактивність залежить від рівня сенсомоторної реактивності спортсменів $\left(\chi^{2}=18,3, \mathrm{P}<0,01\right)$.

Реакція організму переважої більшості спортсменів із середнім та низьким рівнями сенсомоторної реактивності на ортостаз характеризувалась нормальною вегетативною реактивністю (45,8 $\pm 13,8 \%$ та 56,0 $\pm 16,5 \%$, відповідно), тоді як серед спортсменів із високим рівнем сенсомоторної реактивності частка таких осіб була вірогідно нижчою та становила $(14,3 \pm$ $11,1 \%, \mathrm{P}<0,05)$ (рис.).

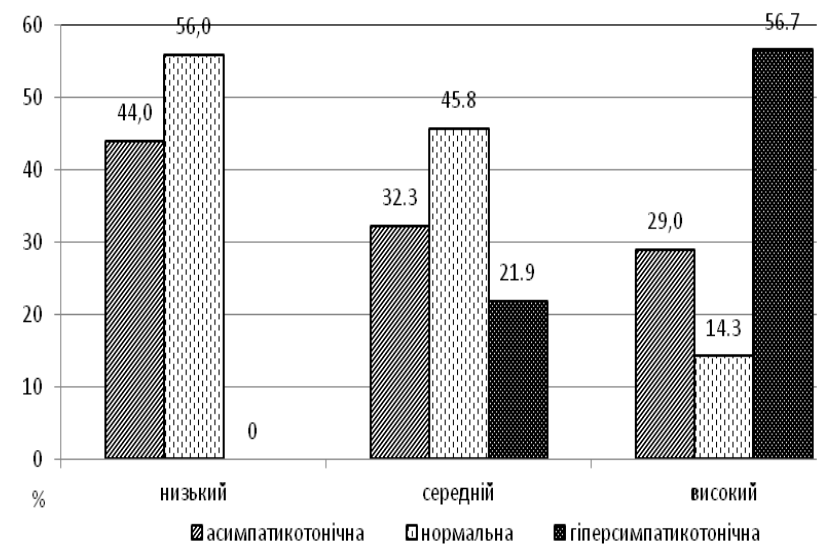

Рис. Розподіл спортсменів (\%) із різним рівнем сенсомоторної реактивності за типом вегетативної реактивності $(\mathrm{n}=32)$

Гіперсимпатикотонія, яка свідчить про вегетативний дисбаланс і пов'язана з напруженням функціонування серцево-судинної системи, визначена у $56,7 \pm 15,7 \%$ спортсменів із високим рівнем сенсомоторної реактивності.

Аналіз показників різних за складністю зорово-моторних реакцій у спортсменів дозволив визначити коротші латентні періоди складних зорово-моторних реакцій (PB1-3 та PB2-3) у дітей із гіперсимпатикотонічною вегетативною реактивністю, порівняно із спортсменами 3 нормальним типом вегетативної реактивності $(\mathrm{P}<0,05)$ (табл. 1$)$.

\section{Таблиця 1}

Показники латентних періодів сенсомоторних реакцій спортсменів залежно від їх вегетативної реактивності $(\mathrm{M} \pm \mathrm{m}, \mathrm{n}=32)$

\begin{tabular}{lccc}
\hline Показники, & \multicolumn{3}{c}{ Вегетативна реактивність } \\
\cline { 2 - 4 } \multicolumn{1}{c}{ мс } & асимпатикотонічна & нормальна & гіперсимпатикотонічна \\
\hline ПЗМР & $272,7 \pm 12,2$ & $305,8 \pm 28,7$ & $270,6 \pm 10,9$ \\
PB 1-3 & $472,2 \pm 24,5$ & $474,8 \pm 35,0$ & $392,0 \pm 20,2^{*}$ \\
PB 2-3 & $536,1 \pm 39,7$ & $586,3 \pm 39,8$ & $484,2 \pm 18,4^{*}$ \\
\hline
\end{tabular}

Примітка: * - $\mathrm{P}<0,05$, вірогідні відмінності порівняно із групою спортсменів із нормальною вегетативною реактивністю.

Для встановлення ступеня впливу сенсомоторних функцій спортсменів на їх вегетативний гомеостаз розраховано внесок рівня сенсомоторної реактивності у показники варіабельності серцевого ритму спортсменів (табл. 2).

У спортсменів із різним рівнем сенсомоторної реактивності спостерігали вірогідні відмінності майже за всіма показниками ВСР. Зокрема, значимо відрізнялися показник $\mathrm{IN}(\mathrm{F}=5,5$; $\mathrm{P}<0,05)$, який відображає ступінь централізації управління серцевим ритмом та $\mathrm{A}_{\mathrm{m} 0}(\mathrm{~F}=5,0 ; \mathrm{P}<0,05)$, збільшення якого свід- 
чить про активацію симпатичної ланки вегетативної регуляції серцевого ритму. Дещо менші відмінності встановлено для показника SDNN (F = 4,6; P < 0,05), що відображає загальну варіабельність серцевого ритму та $\operatorname{RMSSD}(\mathrm{F}=4,5 ; \mathrm{P}<0,05)$, який свідчить про високочастотні компоненти серцевого ритму.

\section{Таблиця 2}

Характеристика впливу сенсомоторної реактивності на показники варіабельності серцевого ритму $(\mathrm{n}=32)$

\begin{tabular}{lccc}
\hline \multicolumn{1}{c}{ Показники } & Внесок, \% & F-критерій & $\mathrm{P}$ \\
\hline $\mathrm{NN}$, мс & 2,6 & 0,1 & $>0,05$ \\
SDNN, мc & 43,1 & 4,6 & $<0,05$ \\
RMSSD, мс & 43,1 & 4,5 & $<0,05$ \\
pNN $_{50}, \%$ & 35,5 & 3,3 & $<0,05$ \\
IN, ум. од. & 47,7 & 5,5 & $<0,05$ \\
$\mathrm{M}_{0}$, мc & 7,4 & 1,3 & $>0,05$ \\
$\mathrm{~A}_{\mathrm{m} 0}$ & 45,3 & 5,0 & $<0,05$ \\
TP, Mc $^{2}$ & 33,7 & 3,0 & $<0,05$ \\
VLF, мc $^{2}$ & 32,2 & 2,9 & $<0,05$ \\
LF, мc $^{2}$ & 27,3 & 2,3 & $>0,05$ \\
$\mathrm{HF}$, Mc $^{2}$ & 37,6 & 3,6 & $<0,05$ \\
LF/HF & 23,9 & 1,9 & $>0,05$ \\
\hline
\end{tabular}

Аналіз спрямованості змін показників ВСР вказує на підвищену активність симпато-адреналової системи у спортсменів із високим рівнем сенсомоторного реагування, що підтверджують вірогідно нижчі значення SDNN (52,5 \pm 13,8 мс) та RMSSD (49,1 \pm 12,5 мc), порівняно зі спортсменами 3 низьким рівнем сенсомоторного реагування $(159,4 \pm 50,3$ і 189,2 $\pm 66,1$ мс, відповідно, $\mathrm{P}<0,05)$.

Зниження визначених показників свідчить про посилення симпатичного впливу, який пригнічує активність автономного контуру регуляції у спортсменів із високим рівнем сенсомоторного реагування.

Показник IN характеризувався вірогідно вищими значеннями серед осіб із високим рівнем сенсомоторного реагування (78,0 $\pm 21,2$ ум. од.), порівняно із спортсменами із низьким його рівнем $(26,8 \pm 18,0$ ум. од., $\mathrm{P}<0,05)$, що вказує на напруження регуляторних механізмів їх організму. Крім того, про підвищену активність симпатоадреналової системи у спортсменів із високим рівнем сенсомоторного реагування свідчать вірогідно вищі значення показника $\mathrm{A}_{\mathrm{m} 0}(35,4 \pm 4,8 \%)$, порівняно із спортсменами із низьким його рівнем $(19,8 \pm 6,1 \%, \mathrm{P}<0,05)$.

\section{Обговорення}

Високі показники швидкості обробки зорової інформації та ефективності зорового сприйняття слугують визначальним фактором у досягненні високих спортивних результатів у єдиноборствах (Korobejnikov et al., 2013). Висока «ціна адаптації» спортсменів із високим рівнем сенсомоторної реактивності характеризується напруженням функціонування серцево-судинної системи, зниженням адаптаційних можливостей їх організмy (Sanes, 2003; David and Coppel, 2015; Golovin and Aizman, 2016; Rovnyj and Romanenko, 2016).

Відповідно до одержаних результатів установлено, що вегетативний дисбаланс притаманний більшості спортсменів із високим рівнем сенсомоторної реактивності, які формують групу підвищеного ризику розвитку функціональних відхилень із боку вегетативних систем.

Установлені особливості підтверджують коротші латентні періоди складних зорово-моторних реакцій (PB1-3 та PB2-3) у дітей із гіперсимпатикотонічною вегетативною реактивністю, порівняно із спортсменами з нормальним типом вегетативної реактивності (P < 0,05) (Zaichkowsky, 2012; Shutova and Murav'eva, 2013).

Високий рівень сенсомоторного реагування пов'язаний із напруженням вегетативної регуляції серцевого ритму, яуе супроводжується зниженням парасимпатичних впливів із боку вегетативної нервової системи, що збігається 3 даними наукових досліджень (Opris, 2005; Herpin et al., 2010; Korobeynikov and Korobeynikova, 2014).
За даними Korobeynikov et. al. (2013), збільшення швидкості сенсомоторного реагування в умовах цілеспрямованих тренувань пов'язане зі збільшенням напруження вегетативної регуляції ритму серця за рахунок підвищення симпатичного тонусу, що узгоджується зі зменшенням тривалості та періодичності коливань кардіоінтервалів.

Однак, порівняно із дослідженнями інших авторів, визначено внесок рівня сенсомоторної реактивності у показники варіабельності серцевого ритму спортсменів (Gallese et al., 2009; Korobejnikov et al., 2013; Sartor et al., 2013; Shutova and Murav'eva, 2013).

\section{Висновки}

Високий рівень сенсомоторної реактивності супроводжується напруженням механізмів вегетативної регуляції серцевого ритму, що проявляється високою часткою симпатикотонічного вегетативного тонусу та гіперсимпатикотонічної вегетативної реактивності серед спортсменів із високим рівнем сенсомоторної реактивності, порівняно із спортсменами із середнім та низьким ії рівнями $(\mathrm{P}<0,001)$.

У групах спортсменів із різним рівнем сенсомоторного реагування значимо відрізнялися показники $\mathrm{IN}(\mathrm{F}=5,5 ; \mathrm{P}<0,05)$ та $\mathrm{A}_{\mathrm{m} 0}(\mathrm{~F}=5,0 ; \mathrm{P}<0,05)$. Дещо менші відмінності встановлено для показника $\mathrm{SDNN}(\mathrm{F}=4,6 ; \mathrm{P}<0,05)$, що відображає загальну варіабельність серцевого ритму та RMSSD ( $\mathrm{F}=4,5 ; \mathrm{P}<0,05)$, який свідчить про високочастотні компоненти серцевого ритму.

\section{References}

Andrew, A., Flatt, A. A., \& Esco, M. R. (2015). Heart rate variability stabilization in athletes: Towards more convenient data acquisition. Clinical Physiology and Functional Imaging, 36(5), 331-336.

Bartczak, D., Szymański, L., Bodera, P., \& Stankiewicz, W. (2016). Psychoneuroimmunological aspects of cardiovascular diseases: A preliminary report. Central European Journal of Immunology, 41(2), 209-216.

Bellenger, C. R., Fuller, J. T., Thomson, R. L., Davison, K., Robertson, E. Y., \& Buckley, J. D. (2016). Monitoring athletic training status through autonomic heart rate regulation: A systematic review and meta-analysis. Sports Medicine, 46(10), 1461-1486.

Blascovich, J., Seery, M. D., Mugridge, C. A., Norris, R. K., \& Weisbuch, M. (2004). Predicting athletic performance from cardiovascular indexes of challenge and threat. Journal of Experimental Social Psychology, 40(5), 683-688.

Bundzen, P. V., Korotkov, K. G., Korotkova, A. K., Mukhin, V. A., \& Priyatkin, N. S. (2005). Psychophysiological correlates of athletic success in athletes training for the Olympics. Human Physiology, 31(3), 316-323.

Coppel, D. B. (2015). Psychological aspects of sports medicine. Current Physical Medicine and Rehabilitation Reports, 3(1), 36-42.

Crollen, V., Albouy, G., Lepore, F., \& Collignon, O. (2017). How visual experience impacts the internal and external spatial mapping of sensorimotor functions. Scientific Reports, 7(1), 1022.

Fedorowski, A., \& Melander, O. (2013). Syndromes of orthostatic intolerance: A hidden danger. Journal of Internal Medicine, 273(4), 322-335.

Gallese, V., Rochat, M., Cossu, G., \& Sinigaglia, C. (2009). Motor cognition and its role in the phylogeny and ontogeny of action understanding. Developmental Psychology, 45(1), 103-113.

Golovin, M. S., \& Aizman, R. I. (2016). Audiovisual stimulation modulates physical performance and biochemical and hormonal status of athletes. Bulletin of Experimental Biology and Medicine, 161(5), 638-642.

Herpin, G., Gauchard, G. C., Lion, A., Collet, P., Kellerc, D., \& Perrin, P. P. (2010). Sensorimotor specificities in balance control of expert fencers and pistol shooters. Journal of Electromyography and Kinesiology, 20(1), 162-169.

Kolesnikova, L., Dzyatkovskaya, E., Rychkova, L., \& Polyakov, V. (2015). New approaches to identifying children of psychosomatic disorders risk group. Procedia - Social and Behavioral Sciences, 214, 882-889.

Korobejnikov, G. V., Korobejnikova, L. G., \& Makarchuk, N. J. (2013). Osobennosti vegetativnoj reguljacii ritma serdca u sportsmenov $\mathrm{s}$ razlichnym urovnem sensomotornogo reagirovanija [Features of vegetative regulation of heart rhythm in athletes with different levels of sensorimotor response]. Scientific Notes of the Taurida National University named after V. I. Vernadsky, 26(65), 89-97 (in Russian). 
Korobeynikov, G., \& Korobeynikova, L. (2014). Functional brain asymmetry and cognitive functions in elite wrestlers. International Journal of Wrestling Science, 4(1), 26-34.

Kraus, U., Schneider, A., Breitner, S., Hampel, R., Rückerl, R., Pitz, M., Geruschkat, U., Belcredi, P., Radon, K., \& Peters, A. (2013). Individual daytime noise exposure during routine activities and heart rate variability in adults: A repeated measures study. Environ Health Perspect, 121(2), 607-612.

Majdannyk, V. G., Smijan, O. I., Bynda, T. P., \& Savel'jeva-Kulyk, N. O. (2014). Vegetatyvni dysfunkcii' u ditej [Autonomic dysfunction in children]. Sumy State University, Sumy. Sums'kyj derzhavnyj universytet, Sumy (in Ukrainian).

Makarenko, M. V., \& Lyzohub, V. S. (2011). Ontohenez psykhofiziolohichnykh funktsiy lyudyny [Ontogenesis of physiological functions of human]. Vertykal', Cherkasy (in Ukrainian).

Nakahara, H., Doya, K., \& Hikosaka, O. (2001). Parallel cortico-basal ganglia mechanisms for acquisition and execution of visuomotor sequences - A computational approach. Journal of Cognitive Neuroscience, 13(5), 626-647.

Nicolas, M., Vacher, P., Martinent, G., \& Mourot, L. (2016). Monitoring stress and recovery states: Structural and external stages of the short version of the RESTQ sport in elite swimmers before championships. Journal of Sport and Health Science, 1-12.

Nikolaeva, E., \& Merenkova, V. (2014). The influence of the children's inner health picture on their heart rate regulation. Procedia - Social and Behavioral Sciences, 159, 87-90.

Opris, I. (2005). Neural circuitry of judgment and decision mechanisms. Brain Research Reviews, 48 (3), 509-526.

Phukan, J., Albanese, A., Gasser, T., \& Warner, T. (2011). Primary dystonia and dystonia-plus syndromes: Clinical characteristics, diagnosis, and pathogenesis. Lancet Neurology, 10(12), 1074-1085.

Rimmele, U., Seiler, R., Marti, B., Wirtz, P. H., Ehlert, U., \& Heinrichs, M. (2009). The level of physical activity affects adrenal and cardiovascular reactivity to psychosocial stress. Psychoneuroendocrinology, 34(2), 190-198.

Rizzolatti, G., Fogassi, L., \& Gallese, V. (2000). Cortical mechanisms subserving object grasping and action recognition: A new view on the cortical motor functions. The New Cognitive Neurosciences, 2, 539-552.
Rovnyj, A. S., \& Romanenko, V. V. (2016). Model'nye harakteristiki sensomotornyh reakcij i specificheskih vosprijatij edinoborcev vysokoj kvalifikacii [Model characteristics of sensorimotor reactions and specific perceptions of martial artists of high qualification]. Edinoborstva, 1, 54-57 (in Russian).

Sanes, J. N. (2003). Neocortical mechanisms in motor learning. Current Opinion in Neurobiology, 13(2), 225-231.

Sartor, F., Vailati, E., Valsecchi, V., Vailati, F., \& Torre, A. (2013). Heart rate variability reflects training load and psychophysiological status in young elite gymnasts. Journal of Strength and Conditioning Research, 27(10), 2782-2790.

Shutova, S. V., \& Murav'eva, I. V. (2013). Sensomotornye reakcii kak harakteristika funkcional'nogo sostojanija CNS [Sensory motor reactions as a characteristic of the functional state of the central nervous system]. Vestnik Tambovskogo universiteta. Serija: Estestvennye i tehnicheskie nauki, 18 (5), 2831-2840 (in Russian).

Suetake, N., Morita, Y., Suzuki, D., Lee, K., \& Kobayashi, H. (2010). Evaluation of autonomic nervous system by heart rate variability and differential count of leukocytes in athletes. Health, 2(10), 1190-1198.

Task force of the European Society of Cardiology the North American Society of Pacing Electrophysiology. Heart rate variability: Standards of measurement, physiological interpretation, and clinical use (1996). Circulation, 93, 1043-1065.

Thayer, J. F., Yamamoto, S. S., \& Brosschot, J. F. (2010). The relationship of autonomic imbalance, heart rate variability and cardiovascular disease risk factors. International Journal of Cardiology, 141(2), 122-131.

Tufnell, G. (2005). Stress and reactions to stress in children. Psychiatry, 4(7), 69-72.

Vejn, A. M. (2003). Vegetativnye rasstroystva: Klinika, diagnostika, lechenie [Autonomic dysfunction: Clinical features, diagnosis, treatment]. Meditsinskoe Informatsionnoe Agentstvo, Moscow (in Russian).

Veyn, A. M. (2003). Vegetative disorders: Clinic, diagnostics, treatment [Autonomic dysfunction: Clinical features, diagnosis, treatment]. Medical News Agency, Moscow (in Russian).

Zaichkowsky, L. (2012). Psychophysiology and neuroscience in sport: Introduction to the special issue. Journal of Clinical Sport Psychology, 6(1), 1-5. 